\title{
Treinamento de força muscular na reabilitação pulmonar em pacientes com DPOC: Uma revisão descritiva
}

\author{
Ana Carolina S. Sampaio, ${ }^{1,2}$ Felipe Cortopassi, ${ }^{1}$ Yves Raphael Souza, ${ }^{1,2}$ Patrícia H. Frasson, ${ }^{1,2}$ \\ Rogério Rufino, ${ }^{1}$ Cláudia Henrique da Costa, ${ }^{1}$ Kenia Maynard $^{1,2 *}$
}

\section{Resumo}

Introdução: A doença pulmonar obstrutiva crônica (DPOC)é uma patologia caracterizada pela obstrução progressiva do fluxo aéreo, parcialmente ou não totalmente reversível, causando prejuízos funcionais. Associado a tais limitações há também a disfunção muscular periférica. Existem evidências de que alterações musculoesqueléticas relacionadas à inatividade física repercutem negativamente no prognóstico dos pacientes com DPOC. Dessa forma, o fortalecimento muscular nestes indivíduos proporciona, além do aumento da força muscular, melhora da capacidade funcional e da qualidade de vida. Objetivos: Identificar os aparelhos utilizados para treinamento de força muscular e a eficácia dos programas de reabilitação pulmonar (PRP) em pacientes com DPOC. Métodos: Revisão narrativa com busca sistemática nas bases de dados Scielo, Pubmed, Medline e Tripdatabase, dos artigos publicados no período de 2005 a 2016. Resultados: Foram selecionados 24 estudos e descritos os tipos de equipamentos utilizados para o treino de força e os resultados dos programas de reabilitação. Conclusões: Os equipamentos de musculação são os mais utilizados para este fim, porém opções mais viáveis e mais versáteis produzem os mesmos resultados, além disso, em todos os estudos, os PRP produziram resultados significativos.

Descritores: Doença pulmonar obstrutiva crônica (DPOC); Reabilitação pulmonar; Fortalecimento muscular; Disfunção muscular periférica; Aparelhos para treinamento muscular; Alta intensidade.

\section{Abstract \\ Muscle strength training in pulmonary rehabilita- tion of COPD patients: A sistematic review}

Introduction: Chronic obstructive pulmonary disease (COPD) is characterized by progressive airflow obstruction, partially or not fully reversible, causing functional impairment. It is also associated with systemic limitations such as peripheral muscle disease; there is evidence that musculoskeletal disorders related to the physical inactivity presents a negative effect on the prognosis of COPD patients. Thus, peripheral muscles training in COPD patients can provide an increase in muscle strength, improving functional capacity and quality of life. Objectives: To identify the devices used for muscle strength training and the effectiveness of the pulmonary rehabilitation program (PRP) in patients with COPD. Method: The study is a systematic review in the databases such as Scielo, Pubmed, Medline and Tripdatabase, with publications from 2005 to 2016. We have selected 24 studies that described the types of equipment used for strength training, and the results of the pulmonary rehabilitation program. Results: Our analysis
1. Departamento de Pneumologia. Hospital Universitário Pedro Ernesto. Universidade do Estado do Rio de Janeiro, Rio de Janeiro, RJ, Brasil.

2. Curso de Fisioterapia. Universidade Veiga de Almeida, Rio de Janeiro, RJ, Brasil.

*Endereço para correspondência:

Estrada dos Bandeirantes 7777 bloco 1 apartamento 606

Rio de Janeiro, RJ. CEP: 22783-115.

E-mail: kenia.msilva@gmail.com

Revista HUPE, Rio de Janeiro, 2016;15(4):356-370

doi: 10.12957/rhupe.2016.31617

Recebido em 03/04/2017. Aprovado em 04/08/2017.

showed that the most frequent used equipment are the fitness equipment, however, more viable and more versatile options produce the same results, and in all studies, PRP produced significant results.

Keywords: Chronic Obstructive Pulmonary Disease (COPD); Pulmonary rehabilitation; Muscle strengthening; Peripheral muscle dysfunction; Apparatus for muscle training; High intensity.

\section{Resumen}

Entrenamiento de la fuerza muscular para rehabilitación pulmonar de los pacientes con EPOC: Una revisión sistemática

Indrodución: La enfermedad pulmonar obstructiva crónica (EPOC) es uma enfermedad caracterizada por la obstrucción progresiva del flujo aéreo, parcialmente o no completamente reversible, provocando deterioro funcional. Otro factor asociado con tales limitaciones es la disfunción muscular periférica. Existe evidencia de que los cambios musculoesqueléticos relacionados a inactividad física demonstran el efecto negativo em el pronóstico de los pacientes con EPOC. Por lo tanto, estos individuos proporcionan fortalecimiento muscular, así como el aumento de la fuerza muscular, mejora el estado funcional y la calidad de vida. Método: Tratase de una revisión sistemática realizada por médio de una búsqueda sistemática en las bases de datos Scielo, Pubmed, Medline y Tripdatabase, se realizo, el año de publicación de los artículos fueron incluidos entre 2005 y 2016. Se seleccionaron 24 estudios, y describe los tipos de equipos utilizados para el entrenamiento la fuerza y los resultados de los programas de rehabilitación. Objetivos: Identificar los dispositivos que se utilizan para el entrenamiento de la fuerza muscular y la eficacia del programa de rehabilitación 
pulmonar (PRP) en pacientes com EPOC. Resultados: Se ha encontrado que el equipo de entrenamiento con pesas son los más utilizados para este fin, pero las opciones más viables y más versátiles producen los mismos resultados, y por otra parte, em todos los estudios, PRP há producido resultados significativos.

\section{Introdução}

A intolerância ao exercício físico em pacientes com Doença Pulmonar Obstrutiva Crônica (DPOC) resulta do comprometimento da função pulmonar. ${ }^{1}$ A disfunção muscular periférica observada, a perda de massa magra, a diminuição da força e resistência muscular são fatores importantes para a limitação da capacidade de realização de exercícios desses pacientes e atividades da vida diária (AVDs). ${ }^{2-5}$

A redução da massa muscular, a incapacidade funcional pelo desuso, fatores nutricionais e fatores metabólicos, baixa capacidade oxidativa muscular estão associadas a fraqueza e a consequente dispneia.-9 Estudos demonstram que o quadríceps é significativamente mais comprometido quando comparado aos peitorais ou grande dorsal. Nos membros superiores a redução da força é maior nos músculos do ombro. ${ }^{10}$

O treinamento de força muscular nos programas de reabilitação pulmonar (PRP) pode resultar em melhora da qualidade de vida, quando comparado ao exercício aeróbio.1-14 Poucos estudos científicos têm destacado as vantagens da prescrição desse tipo de atividade realizada em ambulatório e ambiente domiciliar, com equipamentos acessíveis, uma vez que os pacientes e os serviços públicos em geral não têm acesso aos aparelhos elaborados para este fim, apesar das recomendações das diretrizes da saúde pública. ${ }^{15}$

O novo modelo de atenção básica com foco na recuperação, prevenção e promoção da saúde, contempla atividade física, recomendando a realização durante 30min por dia, no mínimo, intensidade moderada, intencionando o desenvolvimento ou a manutenção da capacidade funcional do paciente, melhorando sua qualidade de vida (QV). A caminhada é a atividade física mais recomendada, porém a literatura mostra que muitos pacientes não saem para caminhar, podese supor que a inserção do treinamento de força com equipamentos acessíveis, realizada em grupo, pode estimular esses pacientes à prática da atividade física da reabilitação pulmonar (RP). ${ }^{16}$

O presente estudo pretende realizar uma revisão descritiva nos últimos 11 anos, tendo como objetivo identificar e descrever os aparelhos utilizados para
Palabras clave: Enfermedad pulmonar obstructiva crónica (EPOC); Rehabilitación pulmonar; Fortalecimiento muscular; Disfunción muscular periférica; Aparato para entrenamiento de los músculos; Alta intensidade de los músculos; Alta intensidade

desenvolver e treinar a força muscular e a eficácia dos programas de reabilitação pulmonar em pacientes com DPOC.

\section{Metodologia}

Estudo de revisão descritiva, aborda características e informações relevantes de artigos e teses sobre tipos de programas de reabilitação pulmonar, aparelhos utilizados para realizar treinamento de força muscular. Utilizados bancos de dados eletrônicos: Pubmed, Scielo, Medline, Tripdatabase. Palavras-chave usadas: "Doença pulmonar obstrutiva crônica", "disfunção muscular periférica", "fortalecimento muscular", "alta intensidade", "aparelhos para treinamento muscular", "high intensity","muscle strengthening", "pulmonary rehabilitation", "Chronic obstructive pulmonary disease - COPD", "peripheral muscle dysfunction". Critérios de inclusão para seleção de artigos: artigos experimentais, pacientes com DPOC, artigos ou teses nas línguas portuguesa e inglesa, publicados de 2005 a 2016. Excluídos artigos de revisão e artigos não relacionados à proposta do estudo. $\mathrm{O}$ processo de seleção dos artigos é descrito no fluxograma na Figura 1.

A busca resultou em 44 artigos e, após a análise, excluíram-se 12 , pois não foram publicados no período estabelecido, 6 por serem artigos de revisão, e outros 4 por não especificarem os tipos de exercícios utilizados no programa de reabilitação ou por não se encaixarem na proposta do estudo atual (Figura 1). Foram selecionados 23 artigos: 7 não citam o tipo de equipamento utilizado no treinamento de força muscular, 1 não utiliza equipamentos para este fim, pois faz o uso da técnica de facilitação neuromuscular proprioceptiva (FNP). Dos 16 artigos que citam os equipamentos utilizados no treinamento de força, 4 usaram somente os aparelhos de musculação para treinamento muscular, enquanto outros 4 estudos utilizaram aparelhos de musculação associado a outros equipamentos, ou seja, em 8 artigos foram citados aparelhos de musculação como método para treinamento muscular. Foram encontrados 4 artigos usando halteres para este fim, porém somente um utilizou isoladamente. Houve ainda 1 último artigo 


\section{Artigo de revisão}

excluido por ser uma teste de mestrado não publicada. As características dos artigos selecionados são apresentadas na Tabela 1.

Tivemos 2 artigos que citaram a corda elástica como material utilizado no treino de força, e a faixa elástica também foi usada para este fim em outros 2 estudos. Pesos livres, barras paralelas, sacos de areia, tábua de quadríceps, esteira rolante inclinada, bicicleta ergométrica com carga, dinamomêtro isocinético, sistema de roldanas, polia simples foram citados somente uma vez. Os programas de reabilitação pulmonar (PRP) obtiveram resultados significativos em todos os estudos avaliados, as variáveis mais citadas foram a capacidade funcional (CF) e qualidade de vida (QV).

\section{Resultados}

O exercício físico e treinamento de força muscular com carga é bem descrito na literatura como parte essencial da reabilitação de pacientes com DPOC, fundamental para minimizar o impacto do descondicionamento físico dos indivíduos, melhorarando a sua CF e QV.

Roceto e colaboradores. ${ }^{17}$ avaliaram a eficácia do programa de reabilitação pulmonar, em 14 pacientes DPOC moderado-grave, que responderam ao Chronic Respiratory Questionnaire (CRQ), tiveram as medidas das pressões inspiratória e expiratória máxima (PImáx e PEmáx) coletadas e percorreram a distância máxima

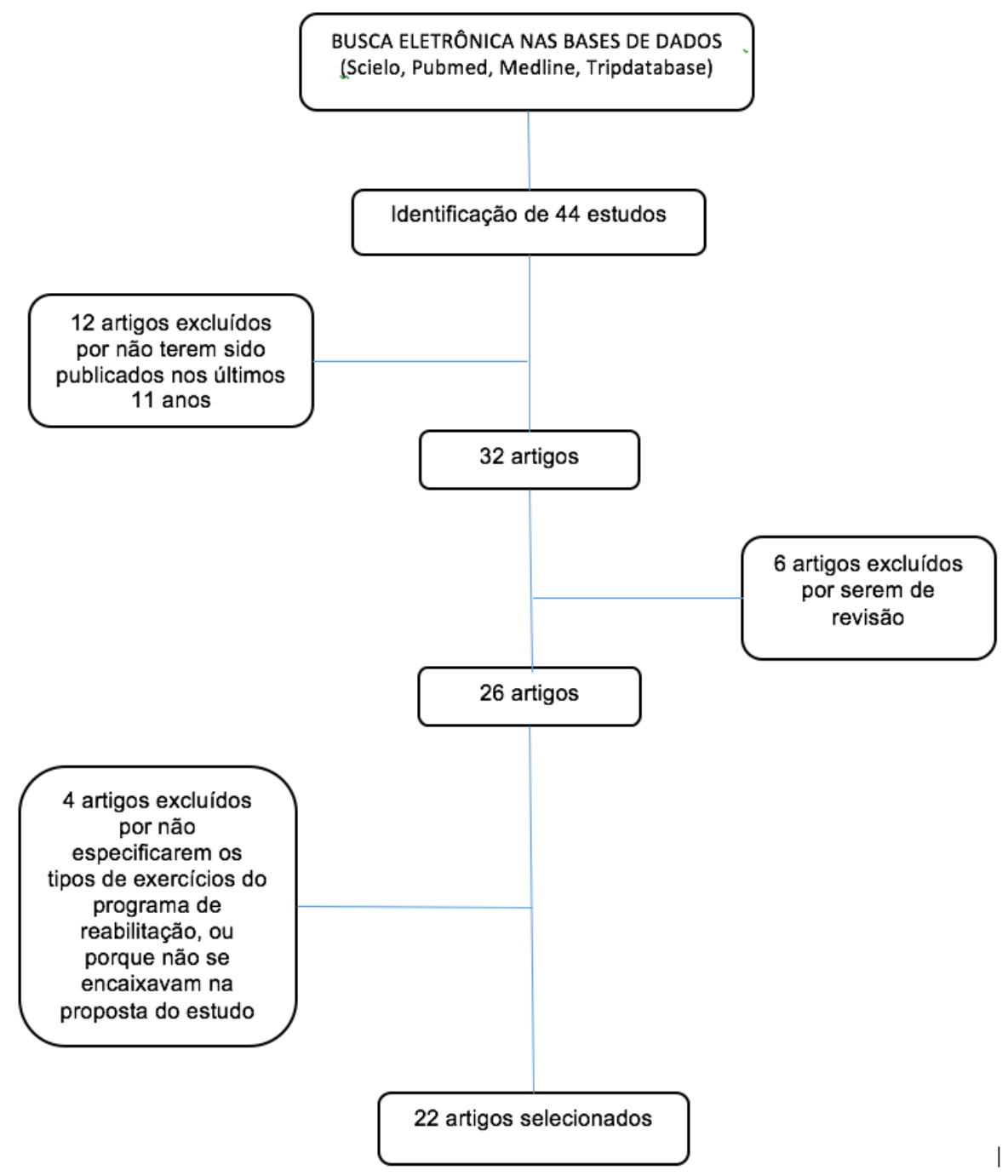

Figura 1. Seleção dos artigos analisados nesta revisão. 
Ana Carolina S. Sampaio e cols. • Treinamento de força muscular na reabilitação pulmonar em pacientes com DPOC: Uma revisão descritiva

Tabela 1. Lista de artigos selecionados no estudo sobre Treinamento de força muscular na reabilitação pulmonar em pacientes com DPOC.

\begin{tabular}{|c|c|c|c|}
\hline Código & $\begin{array}{c}\text { Tipo de } \\
\text { estudo }\end{array}$ & Amostra & $\begin{array}{c}\text { Tipo de } \\
\text { intervenção }\end{array}$ \\
\hline $\begin{array}{l}\text { Ribeiro et } \\
\text { al. (2005) }\end{array}$ & $\begin{array}{l}\text { Ensaio clíni- } \\
\text { co não ran- } \\
\text { domizado }\end{array}$ & $\begin{array}{l}\text { DPOC leve a } \\
\text { moderada, } \\
\mathrm{n}=10\end{array}$ & $\begin{array}{l}\text { Tr e i n a m e } \mathrm{n} \text { t o } \\
\text { aeróbio, treino re- } \\
\text { sistido para MMSS } \\
\text { e fortalecimento } \\
\text { da musculatura res- } \\
\text { piratória }\end{array}$ \\
\hline
\end{tabular}

\begin{tabular}{c|l|l|}
$\begin{array}{c}\text { Zanchet et } \\
\text { al. (2005) }\end{array}$ & $\begin{array}{l}\text { Ensaio clíni- } \\
\text { co não ran- } \\
\text { domizado }\end{array}$ & DPOC, $\mathrm{n}=27$ \\
& \\
& \\
\hline $\begin{array}{l}\text { Roceto et } \\
\text { al. (2007) }\end{array}$ & $\begin{array}{l}\text { Estudo lon- } \\
\text { gitudinal } \\
\text { prospectivo }\end{array}$ & $\begin{array}{l}\text { DPOC mod- } \mathrm{g} \text { gave, } \mathrm{n}=14 \\
\text { gra }\end{array}$ \\
\hline
\end{tabular}

Exercícios calistênicos para aquecimento, fortalecimento muscular para MMSS (flexão do cotovelo, flexão do ombro e abdução do ombro), treino aeróbio e alongamentos

prospectivo grave, $\mathrm{n}=14$

Alongamento global, reeducação diafragmática contrarresistida, exercícios abdominais, calistenia para MMSS, exercícios resistidos para MMSS, exercício aeróbio e relaxamento e orientação para exercícios domiciliares

\begin{tabular}{|c|c|c|c|c|c|c|}
\hline $\begin{array}{l}\text { Cecins et } \\
\text { al. (2008) }\end{array}$ & $\begin{array}{l}\text { Estudo lon- } \\
\text { gitudinal } \\
\text { prospectivo }\end{array}$ & $\begin{array}{l}\text { D P O C , } \\
n=187\end{array}$ & $\begin{array}{l}\text { Exercício aeróbio, } \\
\text { fortalecimento } \\
\text { muscular e treino } \\
\text { de resistência para } \\
\text { MMSS e MMII, ori- } \\
\text { entações domicil- } \\
\text { iares }\end{array}$ & $\begin{array}{l}\text { Capacidade fun- } \\
\text { cional (TC6M), } \\
\text { qualidade de vida } \\
\text { (CRQ), número } \\
\text { de internações, } \\
\text { quantidade de pa- } \\
\text { cientes admitidos, } \\
\text { admissões hospi- } \\
\text { talares por exacer- } \\
\text { bações, totais de } \\
\text { leitos por dia e o } \\
\text { custo total de hos- } \\
\text { pitalização }\end{array}$ & $\begin{array}{l}\text { Não cita os equipa- } \\
\text { mentos utilizados }\end{array}$ & $\begin{array}{l}\text { Melhora da capaci- } \\
\text { dade funcional, } \\
\text { melhora da qual- } \\
\text { idade de vida, re- } \\
\text { dução do número } \\
\text { de internações, da } \\
\text { quantidade de pa- } \\
\text { cientes admitidos, } \\
\text { de admissões hos- } \\
\text { pitalares por exac- } \\
\text { erbação, redução } \\
\text { dos leitos totais por } \\
\text { dia, e do custo total } \\
\text { de hospitalização. }\end{array}$ \\
\hline
\end{tabular}
cular respiratória lar proprioceptiva (FNP), sem necessidade de equipa-

Os exercícios resistidos foram executados de acordo Yy Questionnaire respiratória (PIn e Pemáx), capacidade funcional (TC6M)

Qualidade de vida
Não cita os equipa- Melhora da capacimentos utilizados dade funcional, melhora da força muscular respiratória (PImáx)

Melhora na qualidade de vida e melhora da força mus(PImáx e PEmáx) mentos

\section{(PImáx e PEmáx)}

-

Melhora da capacidade funcional

(PF), sensação de dispnéia (Escala de latura respiratória (IMC), qualidade de (Escala de Borg), ca(TC6M)

\begin{tabular}{|l|l|}
\hline $\begin{array}{c}\text { Equipamento } \\
\text { utilizado }\end{array}$ & \multicolumn{1}{c}{ Resultados } \\
\hline Halteres & $\begin{array}{l}\text { Melhora da capaci- } \\
\text { dade funcional }\end{array}$ \\
\hline
\end{tabular}




\section{Artigo de revisão}

\begin{tabular}{|c|c|c|c|}
\hline $\begin{array}{l}\text { Dourado et } \\
\text { al. (2009) }\end{array}$ & $\begin{array}{l}\text { Ensaio clíni- } \\
\text { co random- } \\
\text { izado }\end{array}$ & DPOC $n=35$ & $\begin{array}{l}\text { Grupo TF: Treina- } \\
\text { mento resistido/ } \\
\text { Grupo EGBI: Trein- } \\
\text { amento aeróbio e } \\
\text { exercícios resisti- } \\
\text { dos de baixa inten- } \\
\text { sidade/ Grupo TC: } \\
\text { exercícios resisti- } \\
\text { dos, treinamento } \\
\text { aeróbio, treino re- } \\
\text { sistido leve }\end{array}$ \\
\hline
\end{tabular}

V a r i á ve is espirométricas, composição corporal (IMC), qualidade de vida (QQVSG), dispnéia (BDI, índice de dispneia basal), força muscular periférica (teste de repetição máxima 1-RM), capacidade funcional (TC6M).
Grupo TF: Equipamentos de musculação/ Grupo EGBI: Pesos livres, colchonetes, barras paralelas/ Grupo TC: Equipamentos de musculação, pesos livres, barras paralelas
Grupo TF: Melhora da força muscular periférica, melhora da qualidade de vida, melhora da dispneia e da capacidade funcional/ Grupo TC: Melhora da força muscular periférica, melhora da qualidade de vida, dispnéia, capacidade funcional / Grupo EGBI: Melhora da qualidade de vida, dispnéia, capacidade funcional

\begin{tabular}{|c|c|c|}
\hline $\begin{array}{c}\text { Costa et al. } \\
(2010)\end{array}$ & $\begin{array}{l}\text { Estudo lon- } \\
\text { gitudina I } \\
\text { prospectivo }\end{array}$ & DPOC, $n=78$ \\
\hline $\begin{array}{l}\text { Trevisan et } \\
\text { al. (2010) }\end{array}$ & $\begin{array}{l}\text { Estudo lon- } \\
\text { gitudina I } \\
\text { prospectivo }\end{array}$ & DPOC, $n=9$ \\
\hline
\end{tabular}

Aquecimento, exercícios aeróbios, exercícios de treino resistido e alongamentos

Exercícios de fortalecimento da musculatura inspiratória, exercícios para fortalecimento dos músculos abdominais e do quadríceps, higiene brônquica, expansão, desinsuflação pulmonar e alongamento muscular.

\begin{tabular}{|c|l|l|}
$\begin{array}{c}\text { Ike et al. } \\
\text { (2010) }\end{array}$ & $\begin{array}{l}\text { Ensaio clíni- } \\
\text { co random- } \\
\text { izado }\end{array}$ & $\begin{array}{l}\text { DPOC mod- } \\
\text { e r a d a a } \\
\text { muito grave, } \\
\mathrm{n}=16\end{array}$ \\
\hline $\begin{array}{c}\text { Macha- } \\
\text { do et al. } \\
\text { (2011) }\end{array}$ & $\begin{array}{l}\text { Estudo de- } \\
\text { scritivo }\end{array}$ & $\begin{array}{l}\text { DPOC mod- } \\
\text { e r a d a a } \\
\text { grave, n=13 }\end{array}$ \\
\hline
\end{tabular}

Grupo GC: higiene brônquica e reeducação funcional respiratória Grupo GT: por aquecimento, exercícios resistidos e alongamentos de MMSS

Alongamentos, aquecimento, fortalecimento de MMSS e MMII, exercício aeróbio, desaquecimento e alongamento final

\section{Qualidade de vida (QQVSG), capaci- dade funcional (TC6M) \\ Qualidade de vida (SF36), força mus- cular respiratória (manovacuome- tria), força muscu- lar do quadríceps do membro inferior dominante (teste \\ Equipamentos de Melhora da quali- musculação dade de vida e mel- hora da capacidade funcional \\ Tábua de quadrí- Melhora da força ceps da musculatura res- piratória, melhora da capacidade fun- cional, aumento da força de quadríceps e melhora da quali- dade de vida} de repetição máxima - 1-RM), capacidade funcional (TC6M)

\begin{tabular}{l|l|}
$\begin{array}{l}\text { Capacidade fun- } \\
\text { cional de MMSS }\end{array}$ & $\begin{array}{l}\text { Equipamentos de } \\
\text { musculação }\end{array}$ \\
(Pegboard and Ring & \\
Test - PBRT), força & \\
muscular periférica \\
(1-RM)
\end{tabular}

Função pulmonar (espirometria), capacidade funcional (TC6M), dispnéia nas AVDs (Escala London Chest Activity of Daily LivingLCADL), sensação de dispnéia (MRC), qualidade de vida (QQVSG)
Esteira rolante inclinada, bicicleta ergométrica com carga

GT: aumento da força muscular periférica

Melhora da dispneia nas AVDs, melhora da qualidade de vida, melhora da capacidade funcional, melhora da sensação de dispnéia, 
Ana Carolina S. Sampaio e cols. • Treinamento de força muscular na reabilitação pulmonar em pacientes com DPOC: Uma revisão descritiva

\begin{tabular}{|c|c|c|c|c|c|c|}
\hline $\begin{array}{l}\text { Menon et } \\
\text { al. (2012) }\end{array}$ & $\begin{array}{l}\text { Ensaio clíni- } \\
\text { co random- } \\
\text { izado }\end{array}$ & $\begin{array}{l}\text { DPOC, } n=45 \\
\text { Saudáveis, } \\
n=19\end{array}$ & $\begin{array}{l}\text { Grupo DPOC: Ex- } \\
\text { ercícios bilaterais } \\
\text { de extensão de jo- } \\
\text { elho/ Grupo sau- } \\
\text { dáveis: Exercícios } \\
\text { bilaterais de ex- } \\
\text { tensão de joelho }\end{array}$ & $\begin{array}{l}\text { Massa muscular } \\
\text { livre de gordura, } \\
\text { tamanho do quad- } \\
\text { ríceps, força mus- } \\
\text { cular do quadríceps }\end{array}$ & $\begin{array}{l}\text { Dinamômetro iso- } \\
\text { cinético }\end{array}$ & $\begin{array}{l}\text { Aumento da massa } \\
\text { muscular livre de } \\
\text { gordura, aumento } \\
\text { da força muscular } \\
\text { em ambos os gru- } \\
\text { pos }\end{array}$ \\
\hline $\begin{array}{l}\text { Benton et } \\
\text { al. (2013) }\end{array}$ & $\begin{array}{l}\text { Ensaio clíni- } \\
\text { co random- } \\
\text { izado }\end{array}$ & DPOC, $n=19$ & $\begin{array}{l}\text { Grupo RPT: Exercíci- } \\
\text { os aeróbios para } \\
\text { MMSS e MMII e } \\
\text { exercícios resisti- } \\
\text { dos para MMSS e } \\
\text { MMII/ Grupo TRI: } \\
\text { Exercícios resistidos } \\
\text { para MMSS e MMII }\end{array}$ & $\begin{array}{l}\text { Qualidade de vida } \\
\text { (SF-36), força mus- } \\
\text { cular periférica } \\
\text { (teste de repetição } \\
\text { máxima ), re - } \\
\text { sistência muscular } \\
\text { (TC6M) }\end{array}$ & $\begin{array}{l}\text { Halteres, equipa- } \\
\text { mentos de muscu- } \\
\text { lação }\end{array}$ & $\begin{array}{l}\text { Melhora da qual- } \\
\text { idade de vida, } \\
\text { aumento da força } \\
\text { muscular periférica } \\
\text { e resistência mus- } \\
\text { cular dos MMII em } \\
\text { ambos os grupos }\end{array}$ \\
\hline $\begin{array}{l}\text { Sousa et } \\
\text { al. (2014) }\end{array}$ & $\begin{array}{l}\text { Estudo pi- } \\
\text { loto }\end{array}$ & $\begin{array}{l}\text { DPOC grave, } \\
n=10\end{array}$ & $\begin{array}{l}\text { Aquecimento, } \\
\text { treinamento da } \\
\text { musculatura in- } \\
\text { spiratória, trein- } \\
\text { amento aeróbio, } \\
\text { treinamento re- } \\
\text { sistido de mem- } \\
\text { bros superiores e } \\
\text { membrosinferiores } \\
\text { (extensão e flexão } \\
\text { de joelhos), e de- } \\
\text { saquecimento }\end{array}$ & $\begin{array}{l}\text { Dispneia (MRC), } \\
\text { composição corpo- } \\
\text { ral (IMC), função } \\
\text { pulmonar (espiro- } \\
\text { metria), força mus- } \\
\text { cular respiratória } \\
\text { (manovacuome- } \\
\text { tria), capacidade } \\
\text { funcional (TC6M), } \\
\text { transtornos do hu- } \\
\text { mor- ansiedade e } \\
\text { depressão (Escada } \\
\text { HAD), qualidade de } \\
\text { vida (QQVSG) }\end{array}$ & $\begin{array}{l}\text { Não cita os equipa- } \\
\text { mentos utilizados }\end{array}$ & $\begin{array}{l}\text { Melhora da força } \\
\text { muscular res- } \\
\text { piratória (Pimáx), } \\
\text { melhora da capaci- } \\
\text { dade funcional, } \\
\text { melhora da quali- } \\
\text { dade de vida, mel- } \\
\text { hora da ansiedade }\end{array}$ \\
\hline $\begin{array}{l}\text { Costa et al. } \\
(2014)\end{array}$ & $\begin{array}{l}\text { Estudo lon- } \\
\text { gitudinal } \\
\text { restrospec- } \\
\text { tivo }\end{array}$ & $\begin{array}{l}\text { DPOC de } \\
\text { moderada a } \\
\text { grave, } n=112\end{array}$ & $\begin{array}{l}\text { Aquecimento, ex- } \\
\text { ercícios aeróbios, } \\
\text { exercícios de força } \\
\text { muscular periférica } \\
\text { e alongamentos }\end{array}$ & $\begin{array}{l}\text { Qualidade de vida } \\
\text { (QQVSG), capaci- } \\
\text { dade funcional } \\
\text { (TC6M), força mus- } \\
\text { cular periférica (1- } \\
\text { RM) }\end{array}$ & $\begin{array}{l}\text { Equipamentos de } \\
\text { musculação }\end{array}$ & $\begin{array}{l}\text { Melhora da qual- } \\
\text { idade de vida, } \\
\text { aumento da força } \\
\text { muscular periférica }\end{array}$ \\
\hline $\begin{array}{l}\text { Pinto et al. } \\
\text { (2014) }\end{array}$ & $\begin{array}{l}\text { Estudo de- } \\
\text { scritivo }\end{array}$ & DPOC, $n=23$ & $\begin{array}{l}\text { Exercícios domicili- } \\
\text { ares: Alongamento, } \\
\text { exercício aeróbio e } \\
\text { exercícios de força } \\
\text { muscular }\end{array}$ & $\begin{array}{l}\text { Qualidade de vida } \\
\text { (relatos de pa- } \\
\text { cientes) }\end{array}$ & $\begin{array}{l}\text { Não cita os equipa- } \\
\text { mentos utilizados }\end{array}$ & $\begin{array}{l}\text { Melhora da quali- } \\
\text { dade de vida }\end{array}$ \\
\hline $\begin{array}{l}\text { Araujo et } \\
\text { al. (2014) }\end{array}$ & $\begin{array}{l}\text { Estudo de- } \\
\text { scritivo }\end{array}$ & $\begin{array}{l}\text { DPOC grave } \\
\text { e m u i t o } \\
\text { grave, } n=5\end{array}$ & $\begin{array}{l}\text { Exercício aeróbio, } \\
\text { treino de resistên- } \\
\text { cia muscular para } \\
\text { MMSS e M MII } \\
\text { (quadríceps e trí- } \\
\text { ceps sural) }\end{array}$ & $\begin{array}{l}\text { Função pulmonar } \\
\text { (espirometria), ca- } \\
\text { pacidade funcional } \\
\text { (TC6M), qualidade } \\
\text { de vida (LCADL, } \\
\text { BODE), dispnéia } \\
\text { (MRC) }\end{array}$ & $\begin{array}{l}\text { Não cita os equipa- } \\
\text { mentos utilizados }\end{array}$ & $\begin{array}{l}\text { Melhora da capaci- } \\
\text { dade de exercício, } \\
\text { melhora da quali- } \\
\text { dade de vida e re- } \\
\text { dução da dispneia }\end{array}$ \\
\hline $\begin{array}{l}\text { Landal et } \\
\text { al. (2014) }\end{array}$ & $\begin{array}{l}\text { Estudo lon- } \\
\text { gitudinal } \\
\text { prospectivo }\end{array}$ & DPOC $n=30$ & $\begin{array}{l}\text { Exercícios de en- } \\
\text { durance e força } \\
\text { muscular para } \\
\text { quadríceps femo- } \\
\text { ral, bíceps braquial } \\
\text { e tríceps braquial }\end{array}$ & $\begin{array}{l}\text { Qualidade de vida } \\
\text { (QQVSG), dispnéia } \\
\text { (MRC), força mus- } \\
\text { cular (1-RM), força } \\
\text { da musculatura res- } \\
\text { piratória (manovac- } \\
\text { uometria), função } \\
\text { pulmonar (espiro- } \\
\text { metria), capacidade } \\
\text { funcional (TC6M), } \\
\text { composição corpo- } \\
\text { ral (bioimpedân- } \\
\text { cia elétrica-BIA) e } \\
\text { o Índice de Massa } \\
\text { corpórea (IMC). }\end{array}$ & $\begin{array}{l}\text { Não cita os equipa- } \\
\text { mentos utilizados }\end{array}$ & $\begin{array}{l}\text { Correlação da } \\
\text { melhora da mas- } \\
\text { sa magra corporal } \\
\text { com melhora da } \\
\text { dispnéia e força } \\
\text { muscular ex- } \\
\text { piratória }\end{array}$ \\
\hline
\end{tabular}




\section{Artigo de revisão}

\begin{tabular}{clll}
\hline $\begin{array}{c}\text { Pothirat et } \\
\text { al. (2015) }\end{array}$ & $\begin{array}{l}\text { Estudo lon- } \\
\text { gitudinal } \\
\text { prospectivo }\end{array}$ & DPOC, $\mathrm{n}=30$ & Exercícios aeróbios \\
& e resistidos para \\
& MMSS e MMII
\end{tabular}

ospectivo

\begin{tabular}{|c|c|c|c|}
\hline $\begin{array}{l}\text { Zanini et } \\
\text { al. (2015) }\end{array}$ & $\begin{array}{l}\text { Ensaio clíni- } \\
\text { co random- } \\
\text { izado }\end{array}$ & $\begin{array}{l}\text { DPOC mod- } \\
\text { e ra d a a } \\
\text { grave } n=60\end{array}$ & $\begin{array}{l}\text { Grupo PRC: ex- } \\
\text { ercícios aeróbios, } \\
\text { treinamento de } \\
\text { MMSS, com calis- } \\
\text { tenia técnicas de } \\
\text { desobstrução das } \\
\text { vias aéreas, res- } \\
\text { piração frenolabial } \\
\text { e treinamento mus- } \\
\text { cular inspiratório } \\
\text { / Grupo PRE: Ex- } \\
\text { ercícios com carga } \\
\text { progressiva }\end{array}$ \\
\hline $\begin{array}{l}\text { Grosbois et } \\
\text { al. (2015) }\end{array}$ & $\begin{array}{l}\text { Estudo ob- } \\
\text { servacional } \\
\text { retrospec- } \\
\text { tivo }\end{array}$ & $\mathrm{DPOC}_{n}=211$ & $\begin{array}{l}\text { A longamentos, } \\
\text { a qu e cim e n to, } \\
\text { exercícios resisti- } \\
\text { dos para MMSS e } \\
\text { MMIl, exercícios de } \\
\text { equilíbrio }\end{array}$ \\
\hline
\end{tabular}

\begin{tabular}{c|l|l|l}
$\begin{array}{c}\text { Kutukcu et } \\
\text { al. (2015) }\end{array}$ & $\begin{array}{l}\text { Ensaio clíni- } \\
\text { co random- } \\
\text { izado }\end{array}$ & $\begin{array}{l}\text { DPOC mod- } \\
\text { e ra da a a } \\
\text { grave, } \mathrm{n}=42\end{array}$ & $\begin{array}{l}\text { Grupo GT: Exercíci- } \\
\text { os de alongamen- } \\
\text { tos, exercícios re- } \\
\text { sistidos de adução } \\
\text { de ombro, flexão e } \\
\text { abdução de ombro, } \\
\text { flexão e extensão } \\
\text { de cotovelo, ele- } \\
\text { vação escapular e } \\
\text { hiperextensão do } \\
\text { ombro, instruções } \\
\text { de exercícios res- } \\
\text { piratórios em dom- } \\
\text { ićlílo / Grupo GC: } \\
\text { Instrução de ex- } \\
\text { ercícios respiratóri- } \\
\text { os em domicílio }\end{array}$ \\
&
\end{tabular}
função pulmonar $A D L)$, limitação na
Força muscular periférica (teste de repetição máxima), capacidade funcional (TC6M), níveis de dispnéia (mMRC), qualidade de vida (QQVSG)

Halteres, sacos de Aumento da força areia, faixas elásti- muscular, melhora cas da dispneia, melhora da qualidade de vida e melhora da capacidade funcional

Força muscular de MMII (The sit-tostand test (STST- 30 segundos-1 minuto e teste de repetição máxima), função pulmonar, gasometria, capacidade funcional (TC6M)

Não cita equipamentos utilizados

Grupo PRE: Melhora da força de MMII (STST - 30 segundos, STST - 1 minuto, 1RM), melhora da capacidade funcional Grupo PRC: melhora da força de MMII (STST - 30 segundos), melhora da capacidade funcional

Capacidade de exercício (Teste de Degrau de 6 minutos - TD6M, sit-tostand test e o Time up and go- TUG), qualidade de vida (Visual simplificado Respiratory Questionnaire -VSRQ, Maugeri Respiratory Failure Questionnaire - MRF-28 e e VQ11), ansiedade e depressão (Escala HAD), dispnéia e esforço de MMII (Escala de Borg)

Índice de Massa Corpórea (IMC), dispnéia (mMRC), (espirometria), e força muscular dos movimentos de preensão palmar, adução de ombro e flexão de cotovelo (dinamômetro), capacidade funcional de MMSS (ergômetro de braço), capacidade funcional (Glittre realização de AVDs com MMSS (Scale Milliken - MAS)

\begin{tabular}{l|l}
$\begin{array}{l}\text { Não cita os equipa- } \\
\text { mentos utilizados }\end{array}$ & $\begin{array}{l}\text { Aumento da força } \\
\text { de preensão man- } \\
\text { ual, diminuição } \\
\text { da dispnéia e di- } \\
\text { minuição da fadiga } \\
\text { muscular de MMSS, } \\
\text { melhora da capaci- } \\
\text { dade funcional de } \\
\text { MMSS, melhora } \\
\text { da capacidade fun- } \\
\text { cional nas AVDs, no } \\
\text { grupo GT }\end{array}$ \\
\end{tabular}




\begin{tabular}{|c|c|c|c|}
\hline $\begin{array}{l}\text { Ferraresi et } \\
\text { al. (2015) }\end{array}$ & $\begin{array}{l}\text { Ensaio clíni- } \\
\text { co random- } \\
\text { izado }\end{array}$ & $\begin{array}{l}\text { DPOC mod- } \\
\text { e r a d a a } \\
\text { grave, } n=36\end{array}$ & $\begin{array}{l}\text { Grupo RI: Exercíci- } \\
\text { os resistidos de ex- } \\
\text { tensão de joelho, } \\
\text { flexão de joelho, leg } \\
\text { press e exercícios } \\
\text { para membros su- } \\
\text { periores como re- } \\
\text { mada, supino reto } \\
\text { e supino vertical/ } \\
\text { Grupo RC: Exercíci- } \\
\text { os resistidos de ex- } \\
\text { tensão de joelho, } \\
\text { flexão de joelho, } \\
\text { leg press e exercíci- } \\
\text { os para membros } \\
\text { superiores como } \\
\text { remada, supino } \\
\text { reto e supino ver- } \\
\text { tical e treino de } \\
\text { resistência/ Grupo } \\
\text { GC: não realizava } \\
\text { treino físico }\end{array}$ \\
\hline
\end{tabular}

Ramos et Ensaio clíni- DPOC, $n=33$ Grupo TTE: aqueci-
al. (2016) co randomizado

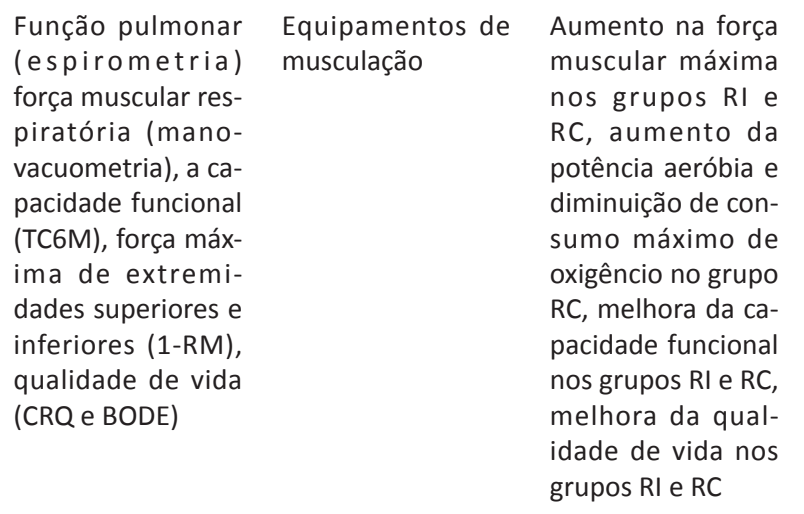

Função pulmonar (espirometria) força muscular respiratória (manovacuometria), a capacidade funcional (TC6M), força máxima de extremidades superiores e inferiores (1-RM), qualidade de vida (CRQ e BODE)

$\begin{array}{ll}\begin{array}{l}\text { Equipamentos de } \\ \text { musculação }\end{array} & \begin{array}{l}\text { Aumento na força } \\ \text { muscular máxima } \\ \text { nos grupos RI e }\end{array} \\ & \text { RC, aumento da } \\ \text { potência aeróbia e } \\ \text { diminuição de con- } \\ \text { sumo máximo de } \\ \text { oxigêncio no grupo } \\ \text { RC, melhora da ca- } \\ \text { pacidade funcional } \\ \text { nos grupos RI e RC, } \\ \text { melhora da qual- } \\ \text { idade de vida nos } \\ \text { grupos RI e RC }\end{array}$

Força muscular e Grupo TTE: Tubos Aumento da força capacidade fun- elásticos/ Grupo muscular, melhocional (TC6M), TC: Equipamentos ria da qualidade qualidade de vida de musculação de vida e melhora (CRQ) da capacidade funcional em ambos os grupos no Teste de Caminhada de 6 minutos (DTC6M).

O PRP teve duração de 12 semanas, associado a orientações domiciliares. Sessões composta de alongamentos, reeducação diafragmática contrarresistida, exercícios abdominais, exercícios calistênicos de membros superiores (MMSS), exercícios resistidos de MMSS, treinamento na bicicleta ergométrica e relaxamento. Para exercícios domiciliares, disponibilizou-se manual com orientações à forma e ao número de repetições de cada um deles, exigindo utilização de materiais de fácil acesso. Ao final, constataram diferença significativa nos domínios do CRQ traduzindo melhora na QV (dispneia, fadiga, função emocional, autocontrole), encontraram diferenças significativas na PImáx e PEmáx. Na DTC6M não se observou diferença significativa.

Pinto e colaboradores ${ }^{18}$ realizaram investigação clínica descritiva sobre intervenção terapêutica so- mente em domicilio, e 23 pacientes DPOC, durante três meses, diariamente, revelaram suas experiências com a doença, seu impacto nas atividades de vida diária (AVDs) e eficácia da reabilitação pulmonar domiciliar (RPD). Para domicílio, os exercícios orientados foram: alongamento; exercício aeróbio, com instrução para uso de esteiras, ruas, escadas e bicicletas para a prática; exercício de força com pesos fornecidos ajustado à condição física; respiração; entrevistas com narrações das experiências de cada participante.

As questões pré-intervenção pediam para o paciente relatar como era sua vida antes da doença, aparecimento/evolução, dia a dia com os sintomas. As perguntas pós-intervenção eram sobre a experiência com RPD, mudanças notadas antes e depois. Os pacientes avaliaram a eficácia da RPD em algumas mudanças significativas, como: estrutura anatômica do tórax, 


\section{Artigo de revisão}

padrões de respiração, massa muscular, estado de independência, autoestima, desejo de viver, sensação de normalidade ao executar tarefas que antes exigiam grandes esforços, alterações na capacidade de andar, vestir-se, subir escadas sem fadiga, interferindo diretamente na melhora da QV.Há relatos detalhados de pacientes que superaram suas limitações físicas e sociais através da RPD, traduzindo em mudanças significativas do dia a dia e no estado mental do indivíduo.

Costa e colaboradore ${ }^{19}$ analisaram os efeitos do PRP na capacidade de exercício, na QV, no estado nutricional de 78 pacientes DPOC, com acompanhamento médico, psicológico (Questionário de Qualidade de Vida do Hospital Saint George-QQVSG), nutricional e treinamento físico. O TC6M foi realizado nestes pacientes antes e após PRP.

Aquecimento, exercícios aeróbicos, exercícios de ganho de força muscular e alongamentos constituíram o programa de reabilitação(PR). O treinamento de força muscular foi realizado em equipamentos de musculação e depois, os pacientes realizavam alongamento dos principais grupos musculares. A QV, avaliada pelo QQVSG, apresentou melhora significativa em todos os domínios, maior facilidade na prática de atividades de vida diária. O TC6M apresentou uma média percorrida significativamente maior após o PRP.

Machado e colaboradore ${ }^{20}$ verificaram a eficácia de um PRP nos efeitos da CF, índice de dispneia e QV em 13 pacientes com DPOC moderada-grave, ex-tabagistas. O grupo foi composto por 20 sessões de treinamento físico, e os pacientes foram avaliados antes e após sete semanas da intervenção. Avaliou-se função pulmonar através da espirometria e a capacidade funcional por meio do TC6M, a Escala London Chest Activity of Daily Living (LCADL) avaliou o impacto da dispneia nas AVDs. A QV foi avaliada através do SGRQ. Para o treinamento com carga, foram feitos testes incrementais para ajustar de acordo com cada paciente, indicando que o peso ideal consistia em $50 \%$ da carga máxima obtida neste teste.

O treinamento de MMSS era realizado com pesos aumentados gradualmente a cada semana $(0,5 \mathrm{Kg})$. Os exercícios com carga para MMII eram realizados em uma esteira rolante inclinada e bicicleta ergométrica com carga ajustada nos testes, aumentando gradativamente a carga a cada dois minutos.

O QQVSG apresentou diferença estatisticamente significativa nos domínios "Sintomas" ( $\mathrm{p}=0,028)$ e "Impacto" ( $\mathrm{p}=0,005)$, porém o domínio "Atividade" não apresentou diferença estatística $(p=0,093)$. Verificou-se também aumento da distância percorrida no TC6M, da QV, mensurada pelo QQVSG.

Cecins e colaboradores ${ }^{21}$ quantificaram resultados de PRP em pacientes DPOC ao longo de 6 anos (19982003) e determinaram os efeitos do programa na redução de admissões hospitalares e das exacerbações. $\mathrm{O}$ treinamento físico era realizado duas vezes por semana por 8 semanas, com equipamentos simples, permitindo que os pacientes os reproduzissem em seu domicílio. Os exercícios presentes no circuito se baseavam em respostas ao domínio "dispneia" do CRQ, objetivando treinar os grupos musculares envolvidos nas atividades que desencadeavam intolerância.

A avaliação antes e após o programa era composta de: TC6M para avaliação da capacidade funcional, CRQ para avaliação da QV, quantificando domínios dispneia, fadiga, função emocional e domínio. Os dados compararam os valores 12 meses antes e 12 meses após o programa.

Ao final do PR, observaram aumento da DTC6M, traduzindo em melhora da capacidade funcional em todos os domínios do CRQ demonstrando melhora da QV. Houve redução de 71 para 38 pacientes admitidos pré e pós $\mathrm{PR}$, diminuição do número total de admissões hospitalares de 127 para 61, redução total leitos/dia de 1.131 para 432 e a média da duração da estadia também se mostrou menor. Reduziram-se os custos de hospitalizações de $\$ 642,408$ para $\$ 245,376$. O estudo mostrou redução nas hospitalizações por exacerbação da DPOC nos 12 meses seguintes ao PRP.

Trevisan e colaboradores ${ }^{22}$ realizaram treinamento de quadríceps e musculatura respiratória, avaliando a eficácia sobre desempenho funcional em indivíduos com 9 pacientes DPOC, composto por exercícios de fortalecimento da musculatura inspiratória, através do Threshold, exercícios para fortalecimento dos músculos abdominais e quadríceps e alongamento muscular. Para fortalecimento do quadríceps, utilizaram tábua de quadríceps com carga inicial de 30\% do teste da repetição máxima (1RM), alcançando máximo de 60\% após algumas sessões.

As variáveis analisadas foram: QV (SF-36), pressões respiratórias máximas, por manovacuômetro digital, força muscular do quadríceps no membro inferior dominante, pelo teste 1RM, PImáx e PEmáx e capacidade de exercício, pelo TC6M. Verificou-se aumento na força dos músculos respiratórios, evidenciada pelo acréscimo na PImáx e PEmáx, média da DTC6M e força muscular do quadríceps. A QV mostrou-se melhor nos domínios dor, vitalidade, limitação por aspectos emocionais. 
Ribeiro e colaboradores ${ }^{23}$ realizaram programa de RP, em 10 pacientes com DPOC, verificando tolerância ao exercício físico, PImáx e PEmáx, pico de fluxo expiratório (PF) e sensação de dispneia após PRP.Submetidos a avaliações antes e após o programa, como: espirometria, avaliação da força da musculatura respiratória, medida de PF e TC6M. Consistiu em treinamento num cicloergomêtro, exercícios com halteres para membros superiores e treinamento de força da musculatura inspiratória. Observaram aumento significativo da DTC6M, porém não foram encontradas diferenças significativas na sensação de dispneia e nos valores espirométricos do PF e da Pemáx.

Ike e colaboradores ${ }^{24}$ avaliaram efeito do exercício com carga para membros superiores em 12 pacientes com DPOC, para o ganho de força e na CF. Eles realizaram 1RM e Pegboard and Ring Test (PBRT) antes e após o tratamento. O teste RM foi realizado tanto para avaliar a carga utilizada nos exercícios como a força muscular antes e depois do programa. PBRT é usado para avaliar CF de MMSS em indivíduos com DPOC.

Os pacientes foram divididos em dois grupos: GC (grupo controle) e GT (grupo do tratamento), o GC realizou condutas de higiene brônquica e reeducação funcional respiratória. Sessões do GT foram compostas por aquecimento, supino sentado, pulley superior frontal (80\% de 1RM), alongamento dos MMSS. Após período de tratamento, verificou-se aumento significativo na força muscular do GT, enquanto no GC não houve diferença significativa. Em relação PBRT, não se observou diferença significativa em nenhum dos dois grupos antes e após as seis semanas de tratamento.

Dourado e colaboradores ${ }^{25}$ investigaram fatores associados à diferença clinicamente significativa da QV após condicionamento físico em 35 pacientes com DPOC, avaliados valores espirométricos, índice de massa corpórea (IMC) e QV, através do SGRQ e dispneia relacionada às AVDs avaliada pelo Baseline dyspnea index (BDI). A força muscular periférica foi mensurada pelo teste 1RM e CF avaliada pelo TC6M.

Os pacientes foram distribuídos em três grupos: treinamento de força (TF), exercícios gerais de baixa intensidade (EGBI), treinamento combinado (TC). O TF consistiu em sete exercícios realizados em aparelhos de musculação, com intensidade entre 50\% e 80\% de 1RM. O EGBI foi composto de caminhada livre, exercícios gerais de baixa intensidade, com pesos livres, em colchonetes e barras paralelas. O TC era composto de $\mathrm{TF}$, exercícios gerais de baixa intensidade com metade do volume do EGBI.
Após PRP, a força apresentou resultados mais consistente no TF e no TC. Vinte e quatro, apresentaram melhora clinicamente significativa no escore total do SGRQ, traduzindo em uma melhora da QV, porém não houve interferência do tipo de exercício na QV, na capacidade de exercício e na dispneia. A função pulmonar e a composição corporal não mostraram alterações em nenhum dos grupos.

Grosbois e colaboradores, ${ }^{26}$ num estudo observacional retrospectivo, avaliaram o resultado do PRP em casa, a longo prazo, sobre capacidade de exercício, QV, ansiedade, depressão em 211 pacientes com DPOC. As avaliações também foram realizadas em casa, antes e depois do PRP, após 6 meses, e novamente após 12 meses.

Antes de iniciar o programa, realizaram programa de educação terapêutica. Foi determinada a FC ideal, em exercícios de resistência na bicicleta ergométrica. A Escala de Borg mensurou a percepção de esforço.

Propuseram três tipos de exercícios para fortalecimento muscular de MMSS e MMII para os participantes, usando pesos e halteres e/ou faixas elásticas. Para avaliação da capacidade funcional, realizaram Teste de Degrau de 6 minutos (TD6M), assim como o sit-to-stand test e o Time up and go (TUG). A Escala de Borg avaliou a dispneia e esforço de MMII. A QV foi avaliada por meio de três questionários: $\mathrm{O}$ Visual simplificado Respiratory Questionnaire(VSRQ), Maugeri Respiratory Failure Questionnaire-MRF-28 (específico para pacientes que fazem uso de oxigenoterapia domiciliar prolongada) e VQ11, composto por 11 itens, com cinco níveis de resposta e três componentes: funcionais, psicológicas e relacionais. A escala Hospital Anxiety and Depression Scale (HAD) avaliou o nível de ansiedade e depressão.

Observou-se melhora significativa em todos os parâmetros estudados, antes e após o PRP. Após seis meses, todas as variáveis avaliadas se mantiveram melhores, com exceção do TUG. O escore da HAD, o escore do VQ11, obtiveram melhoras significativas, comparados aos valores de pré PRP. As outras variáveis não apresentaram diferença significativa.

Aos 12 meses, persistiu a melhora de todos os resultados encontrados. O resultado dos três questionários que avaliam QV, foram estatisticamente diferentes, apresentando melhoras entre 6 e 12 meses, a dispneia obteve melhora nas três avaliações.

Zanchet e colaboradores, ${ }^{27}$ num ensaio clínico não randomizado, avaliaram a eficácia de um PRP, na capacidade de exercício, força da musculatura respiratória e QV em 27 pacientes com DPOC, ex-tabagistas estáveis clinicamente. A avaliação foi feita antes e após 


\section{Artigo de revisão}

o programa, consistindo em avaliação das variáveis espirométricas, a pressão parcial de oxigênio e pressão parcial de dióxido de carbono no sangue arterial, saturação arterial de oxigênio, IMC, utilizou-se também o SGRQ e manovacuometria realizada para aferir as pressões respiratórias máximas, dispneia foi avaliada através da Escala de Borg, e a capacidade funcional por meio do TC6M.

Compuseram as sessões do treinamento físico por exercícios de aquecimento, exercícios de fortalecimento de membros superiores, realizados com 50\% da carga máxima atingida no teste incremental adicional de 0,5 Kg na carga, o artigo não cita os equipamentos utilizados. Realizaram condicionamento aeróbio na bicicleta ergométrica, o desaquecimento consistiu em alongamentos.

Não apresentaram diferenças estatisticamente significativas: IMC, variáveis espirométricas e gasométricas, e sensação de dispnéia após seis semanas de PRP. Houve melhora significativa na distância do TC6M, na carga máxima obtida no teste incremental de membros superiores, na PImáx. No escore do VSRQ, houve redução estatisticamente significativa nos domínios atividades, impacto, no escore total.

Costa e colaboradores ${ }^{28}$ avançaram em seus estudos e num estudo observacional, correlacionaram utilização do teste 1RM com capacidade funcional e QV num PRP, participaram 112 pacientes DPOC de moderada a grave.

O programa de treinamento era composto por esteira ergométrica para exercício aeróbio, aparelhos de musculação, e para determinação da carga máxima realizaram teste de 1RM. O QQVSG avaliou qualidade de vida, a avaliação da capacidade funcional por TC6M, executado antes e após o PRP. Verificou-se diferença estatisticamente significativa no teste de 1RM em todos os exercícios, traduzindo aumento da força muscular, porém não houve correlação entre o teste de 1RM com a capacidade de exercício e QV. Observaram melhora clinicamente significativa nos domínios da avaliação da QV, e aumento na distância percorrida no TC6M.

Sousa e colaboradores ${ }^{29}$ investigaram num estudo piloto efeitos de um programa de RP padrão, composto por exercícios de força e resistência muscular periférica e respiratória em 10 pacientes com DPOC. As avaliações foram antes do programa de treinamento, após 12 sessões e ao final de 5 meses. O escore de mMRC avaliou a dispneia, o IMC foi verificado, as variáveis espirométricas, PImáx e PEmáx, TC6M, teste ergométrico submáximo, avaliação dos transtorno de humor através da escala HAD, o SGRQ avaliou a QV. Para fortalecimento da musculatura respiratória usaram o Threshold, a bicicleta ergométrica para treinamento aeróbio. Não há informações sobre os equipamentos usados para o treino resistido.

Após as 12 sessões, observaram melhora significativa na PImáx, CF e QV, especialmente nos domínios sintomas. Após 5 meses, persistiu essa melhora com aumento não significante. Em relação ao escore ansiedade, após 12 sessões, classificou-se como grau leve, após os 5 meses, o escore diminuiu e os pacientes foram classificados como normais. As demais variáveis não apresentaram diferenças significativas.

Zanini e colaboradores ${ }^{30}$ avaliaram força muscular de MMII em 30 pacientes com DPOC moderada a grave, através do The sit-to-stand test (STST - 30segundos$1 \mathrm{~min})$, comparado ao teste 1RM, considerado padrão-ouro para verificar a força muscular, avaliando resposta de dois grupos: PR convencional e PR específico de força muscular. Realizaram testes de função pulmonar e gasometria, TC6M, teste 1-RM e o STST de 30s e 1min.

A PR convencional consistiu de exercícios aeróbios, em esteira, ou cicloergomêtro, treinamento de MMSS com calistenia com peso leve e ergômetro de braço. No grupo do PR específico, incluíram dois conjuntos de sete exercícios diferentes, com. cargas iniciais equivalentes a 60\%-70\% do 1-RM. A dosagem foi aumentada de acordo cada paciente.

Após o programa, verificou-se que os dois grupos se relacionaram significativamente com a linha de base 1RM, para o STST 30s e 1min. Apresentaram diferenças estatisticamente significativas entre cansaço percebido após 30 segundos do STST, 1 RM e entre STST-1min e 1RM. O principal resultado deste estudo foi:STST -30segundos e STST - 1min mostrou uma correlação significativa com a 1-RM, considerada o padrão-ouro para avaliar a força muscular, em todos os pacientes.

Benton \& Wagner ${ }^{31}$ investigaram os efeitos do treinamento de resistência isolado na QV em 19 pacientes idosos com DPOC, durante PRP, em um grupo de RP tradicional e outro com RP com treino de resistência isolado (TRI). Medical Outcomes Study Short Form 36 (SF-36) avaliou QV, mensurando limitações nas AVDs, deficiências na saúde física e mental. A força muscular foi medida usando supino inclinado no peito: repetição máxima (1RM), o leg press (1RM). O TC6M mediu resistência muscular.

O treinamento do grupo RP tradicional foi composto por ergômetro para braço, esteira e bicicleta ergométrica. Os participantes utilizaram halteres va- 
riando entre 0,5 a 4,5 kg. Para cada exercício a meta era atingir 15 repetições num determinado peso antes de aumentar a carga na sessão seguinte. O PRP com treino de resistência isolado (TRI) consistiu em um conjunto de cinco exercícios resistidos: leg press, supino inclinado, bíceps e tríceps. A carga inicial foi 50\% de 1RM no leg press e supino inclinado.

Entre os grupos não foram observadas diferenças estatisticamente significativas relacionadas à $\mathrm{QV}$, antes e depois do programa de treinamento. Porém, constataram melhora global na pontuação do SF-36. Antes do PRP, força e resistência foram semelhantes nos dois grupos, após o PRP, verificou-se aumento significativo da força muscular e resistência nos MMII. Também houve aumento na DTC6M, embora entre os grupos as melhorias não foram estatisticamente significativas. Nogrupo com TRI, houve aumento de $10 \%$ no leg press 1RM e aumento de $14 \%$ no supino 1RM.

Pothirat e colaboradores ${ }^{32}$ avaliaram a viabilidade e benefícios a longo prazo num programa de treinamento simples realizado em 30 pacientes numa comunidade na Tailândia. Programas deste tipo em países em desenvolvimento são limitados por incluirem equipamentos de alto custo. A proposta para o treino de força foi utilizar equipamentos de baixo custo como halteres, sacos de areia e faixas elásticas, podendo ser implementado noutros hospitais.

O programa de treinamento foi composto por exercícios com intensidade progressiva, inicialmente leve; para treinamento de força de MMSS e MMII utilizaram pesos e cargas resistivas; para resistência, realizaram caminhadas em corredor com superfície plana. A partir do terceiro mês de treinamento, na fase de manutenção, forneceram equipamentos aos pacientes e incentivaram eles a continuarem o treinamento em casa, sem supervisão.

Os grupos musculares selecionados dos MMSS para teste foram: bíceps, tríceps (testados com halter) e peitoral (testado com faixa elástica).Para membros inferiores, o quadríceps foi testado através do levantamento de sacos de areia em $10 \mathrm{RM}$. OTC6M avaliou a capacidade funcional e, para ser considerada uma diferença mínima clinicamente importante, os pacientes deveriam alcançar distância mínima de 54 metros. O mMRC e SGRQ avaliaram níveis de dispneia e QV.

Ao longo dos 12 meses, constataram melhora na dispneia, QV e capacidade funcional, porém o mMRC atingiu a diferença clinicamente significativa $\operatorname{com} 2$, 3 e 9 meses. Já o TC6M e SGRQ no mês 2 e 1, respectivamente.
Landal e colaboradores ${ }^{33}$ investigaram fatores relacionados ao aumento da massa magra corporal (MMC) em 30 pacientes (DPOC) através do programa de treinamento físico de alta intensidade. Foram submetidos à avaliação de $\mathrm{AFVD}$, por monitor que registra gastos energéticos, em diferentes atividades.

A QV foi avaliada através do SGRQ a sensação de dispneia durante as AVDs foi avaliada pela mMRC, RM, manovacuometria, espirometria, TC6M, bioimpedância elétrica (BIA) e IMC.

Exercícios de endurance e força muscular compuseram o programa de treinamento para quadríceps femoral, bíceps e tríceps braquial, não sendo citado o equipamento utilizado. Dezessete pacientes, após treinamento de alta intensidade, apresentaram melhora da mMMC e este evento correlacionou significativamente com melhora da taxa metabólica basal, sensação subjetiva de dispnéia, PEmáx, CVF/VEF1, sugerindo que a mMMC não seja utilizada como variável independente no tratamento da DPOC.

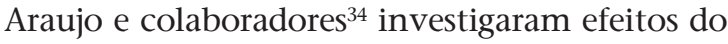
PRP a longo prazo na capacidade funcional, dispneia e risco de mortalidade em 5 pacientes com DPOC grave e muito grave. Trata-se de relato de caso retrospectivo, no período de 1 ano. Extraíram dados espirométricos, antropométricos, DTC6M, índice BODE, escores da escala LCADL e da MRC, reavaliadas após 24 sessões e após um ano. O programa de treinamento físico foi composto de exercícios aeróbios, treino de resistência muscular para MMSS, fortalecimento muscular de quadríceps e tríceps sural. O equipamento utilizado para treino de resistência não foi relatado.

Quatro pacientes apresentaram melhora significativa no TC6M, redução nos escores da LCADL, traduzindo melhora da QV, porém somente um paciente obteve melhora relevante da dispneia e melhora da QV. Quatro pacientes tiveram melhora no índice BODE e, após um ano, alcançaram capacidade de exercício considerada normal, dos quais três apresentaram redução da dispneia na escala mMRC.

Ramos e colaboradores ${ }^{35}$ realizaram ensaio clínico randomizado para comparar os efeitos do treinamento resistido com tubos elásticos, aos efeitos do treinamento convencional com a utilização de aparelhos de musculação sob a força muscular e capacidade funcional em indivíduos com 33 pacientes DPOC moderada. Divididos em dois grupos de treinamento: treino convencional (TC: $\mathrm{n}=17$ ) e treino com tubos elásticos (TTE: $\mathrm{n}=17$ ). As sessões utilizaram tubos elásticos ou aparelhos de musculação para os grupos de TTE e TC, 


\section{Artigo de revisão}

respectivamente.

Após o término do programa de treinamento, observaram aumento significativo da força muscular em ambos os grupos, porém entre os grupos não houve diferença significativa. O TC6M mostrou melhoria significativa pelo aumento da distância percorrida nos dois grupos, correlacionando-se positivamente com força muscular do quadríceps, no entanto, foi maior no TTE. O CRQ avaliou a QV, mostrando-se melhor significativamente nos dois grupos, sem diferenças entre eles. No grupo TTE todos os quatro domínios alcançaram a diferença mínima clinicamente importante, enquanto que no grupo TC somente dois. Também foi constatado que em ambos os grupos houve tendência de melhora de massa livre de gordura, avaliada pela absorciometria.

Ferraresi e colaboradores ${ }^{13}$ compararam efeitos do treinamento resistido, com efeito do treinamento combinado, num período de 12 semanas, na $\mathrm{CF}$, força muscular e QV em 36 pacientes com DPOC de moderada a grave, alocados aleatoriamente em três grupos: TRI, treinamento de resistência combinada (RC) e grupo controle (GC). Avaliados antes e depois do programa de treinamento: função pulmonar, força muscular respiratória, CF, através do desempenho do TC6M, força máxima de extremidades superiores e inferiores, de acordo ao teste RM (1RM) e QV, através do CRQ e do índice BODE.

Cada sessão do grupo TRI foi composta de exercícios resistidos realizados em aparelhos de musculação. As sessões do grupo RC eram compostas de exercícios resistidos com mesma intensidade, mesmo número de repetições e mesmos grupos musculares do grupo TRI, utilizando a metade da freqüência semanal em relação ao TRI para treino de força e outra metade para treino de resistência, com intensidade pré-determinada no teste máximo de exercício.

Não foram observadas diferenças significativas entre os três grupos, porém houve aumento significativo na força muscular máxima nos grupos TRI e RC, sem alterações de força no grupo GC. A potência máxima aeróbia aumentou significativamente no grupo RC e reduziu significativamente o consumo máximo de oxigênio. Os grupos RC e TRI obtiveram aumento significativo DTC6M, sem alterações no GC. A QV se mostrou melhor significativamente em todos os domínios avaliados no CRQ nos grupos TRI e RC, sem mudanças no GC. Também se constatou uma diminuição significativa no índice BODE nos grupos TRI e RC, sem alterações no GC. Observaram maior potência muscular no exercício de leg press a 50\% de
1RM, somente no grupo RC.

Calik-Kutukcu e colaboradores ${ }^{36}$ avaliaram os efeitos do treinamento de força em MMSS no desempenho funcional, realização de AVDs e desempenho ocupacional em 42 pacientes DPOC moderado a grave, distribuídos aleatoriamente no grupo tratamento (GT) e grupo controle (GC).

Avaliados antes e depois do período de treinamento: IMC, mMRC, espirometria e dinamômetro. O teste de capacidade funcional foi realizado num ergômetro de braço. As AVDs foram avaliadas por meio do Glittre-ADL; teste de simulação de transporte de mochila de 2,5 $\mathrm{kg}$ para mulheres e $5,0 \mathrm{~kg}$ para homens, cronometrando pequeno trajeto e avaliando a CF do indivíduo. Mensuraram a saturação de oxigênio, o índice de dispneia e a FC ao longo do teste.

A avaliação da CF na realização de AVDs e níveis de dispneia foram avaliados numa simulação de quatro atividades realizadas em um ciclo. Scale Milliken (MAS) avaliou limitações de atividades de MMSS, atividades bilaterais e unilaterais. The Canadian Occupational Performance Measure (COPM) avaliou graus de dificuldade, suas respectivas importâncias para atividades relatadas pelos pacientes.

Exercícios resistidos compuseram as sessões do GT, todos realizados com pesos livres. Os pacientes dos grupos GT e GC foram instruídos a realizarem exercícios de respiração em domicúlio. Após treinamento, observouse aumento significativo na força de preensão manual no grupo de tratamento, sem alterações significativas no grupo controle. Houve diminuição significativa da percepção da dispneia durante realização de exercício no ergômetro de braço no grupo de tratamento, no grupo controle houve aumento da percepção da dispneia. A fadiga muscular dos braços diminuiu significativamente no grupo de tratamento.

Observaram mudanças significativas na FC e percepção da dispneia durante os testes que avaliaram QV, somente no grupo de tratamento, bem como aumento significativo no número de mudanças de ciclos no teste de AVDs em ambos os grupos, com diminuição significativa da percepção da dispneia no grupo de tratamento, sem alterações no grupo controle, após o treinamento.

Alterações de tempo de MAS, nos domínios limpeza da casa e lavanderia, obtiveram mudanças estatisticamente significantes, com aumento estatisticamente significante no grupo de tratamento. Mudanças nos graus de habilidade dos domínios "Outras atividades em curso" e "Outras atividades integradas" foram sig- 
nificantes em ambos os grupos, com aumento estatisticamente significativo no grupo controle. Observaram alterações nas pontuações do COPM-P, com aumento significativo somente no grupo de tratamento.

Menon e colaboradores ${ }^{37}$ avaliaram respostas do treinamento físico resistido de alta intensidade nas medidas de massa muscular do quadríceps, por técnica de absorciometria de raio-x de dupla energia (DEXA), em 45 pacientes DPOC, comparados a 19 pessoas saudáveis do grupo controle. Compuseram o treinamento físico: exercícios bilaterais de extensão de joelho, num dinamômetro isocinético. O ultrassom mensurou o tamanho do quadríceps, por meio de varredura ao longo do músculo. A força do quadríceps foi avaliada durante a contração máxima isométrica, com joelho a $70^{\circ}$. Ao final do estudo, observaram aumento significativo na massa magra da coxa, na área de secção transversa do reto femoral e espessura do músculo quadríceps em ambos os grupos, maior no grupo DPOC. A contração voluntária máxima do quadríceps melhorou significativamente em ambos os grupos.

\section{Conclusão}

Esta revisão mostrou que os benefícios do treinamento de força muscular publicados foram alcançados, independentemente do tipo de instrumento utilizado. Os aparelhos de musculação foram mais utilizados, porém há outras opções que produzem os mesmos resultados e possuem melhor relação custo-benefício, como os halteres, caneleiras, cordas elásticas, entre outros, possibilitando maior versatilidade e facilidade para a sua aquisição, permitindo a realização dos exercícios domiciliares. A implementação de treinamento de força com aparelhos acessíveis poderá estimular os pacientes DPOC à prática da atividade física na reabilitação pulmonar, contribuindo para a eficácia dos programas instituídos pelo Ministério da Saúde.

\section{Referências}

1. Celli BR, MacNee W, Force AET. Standards for the diagnosis and treatment of patients with COPD: a summary of the ATS/ ERS position paper. Eur Respir J. 2004;23(6):932-946.

2. Maltais F, Decramer M, Casaburi R, et al. An official American Thoracic Society/European Respiratory Society statement: update on limb muscle dysfunction in chronic obstructive pulmonary disease. Am J Respir Crit Care Med. 2014;189(9):e15-62.

3. Schols AM, Slangen J, Volovics L, et al. Weight loss is a reversible factor in the prognosis of chronic obstructive pulmonary disease. Am J Respir Crit Care Med. 1998;157(6 Pt 1):1791-1797.

4. Celli BR, Cote CG, Marin JM, et. al. The body-mass index, airflow obstruction, dyspnea, and exercise capacity index in chronic obstructive pulmonary disease. N Engl J Med.
2004;350(10):1005-1012.

5. Velloso M, Jardim JR. Study of energy expenditure during activities of daily living using and not using body position recommended by energy conservation techniques in patients with COPD. Chest. 2006;130(1):126-132.

6. Seymour JM, Spruit MA, Hopkinson NS, et al. The prevalence of quadriceps weakness in COPD and the relationship with disease severity. Eur Respir J. 2010;36(1):81-88.

7. Ischaki E, Papatheodorou G, Gaki E, et al. Body mass and fatfree mass indices in COPD: relation with variables expressing disease severity. Chest. 2007;132(1):164-169.

8. Natanek SA, Gosker HR, Slot IG, et. al. Pathways associated with reduced quadriceps oxidative fibres and endurance in COPD. Eur Respir J. 2013;41(6):1275-1283.

9. Maltais F, Simard AA, Simard C, et. al. Oxidative capacity of the skeletal muscle and lactic acid kinetics during exercise in normal subjects and in patients with COPD. Am J Respir Crit Care Med. 1996;153(1):288-293.

10. Gosselink R, Troosters T, Decramer M. Distribution of muscle weakness in patients with stable chronic obstructive pulmonary disease. J Cardiopulm Rehabil. 2000;20(6):353-360.

11. Rochester CL, Vogiatzis I, Holland AE, et al. An Official American Thoracic Society/European Respiratory Society Policy Statement: Enhancing Implementation, Use, and Delivery of Pulmonary Rehabilitation. Am J Respir Crit Care Med. 2015;192(11):1373-1386.

12. Spruit MA, Singh SJ, Garvey C, et al. An official American Thoracic Society/European Respiratory Society statement: key concepts and advances in pulmonary rehabilitation. Am J Respir Crit Care Med. 2013;188(8):e13-64.

13. Zambom-Ferraresi F, Cebollero P, Gorostiaga EM, et al. Effects of Combined Resistance and Endurance Training Versus Resistance Training Alone on Strength, Exercise Capacity, and Quality of Life in Patients With COPD. J Cardiopulm Rehabil Prev. 2015;35(6):446-453.

14. Ortega F, Toral J, Cejudo P, et al. Comparison of effects of strength and endurance training in patients with chronic obstructive pulmonary disease. Am J Respir Crit Care Med. 2002;166(5):669-674.

15. Malta DC, Silva MM, Albuquerque GM, et al. [The implementation of the priorities of the National Health Promotion Policy, an assessment, 2006-2014]. Cien Saude Colet. 2014; 19(11):43014312.

16. Pitta F, Troosters T, Probst VS, et al. Potential consequences for stable chronic obstructive pulmonary disease patients who do not get the recommended minimum daily amount of physical activity. J Bras Pneumol. 2006:32(4):301-308.

17. Roceto L, Takara L, Machado L, et al. Eficácia da reabilitação pulmonar uma vez na semana em portadores de doença pulmonar obstrutiva. Brazilian Journal of Physical Therapy. 2007;11: 475-480.

18. Pinto JMdS, Martín-Nogueras A, Nations M. Illness experiences of persons with chronic obstructive pulmonary disease: self-perceived efficacy of home-based pulmonary rehabilitation. Cadernos de Saúde Pública. 2014;30:1270-1280.

19. Costa CC, Baldessar LZ, Canterle DB, et al. Analysis of results of a pulmonary rehabilitation program in patients with chronic obstructive pulmonary disease. Revista da AMRIGS. 2010;54(4):406-410.

20. Machado FRL, Correa KS, Rabahi MF. Effects of combined physical exercise in dyspnea, functional capacity and quality of life in patients with COPD in a private clinic. ASSOBRAFIR Ciência. 2011;2(2):19-28.

21. Cecins N, Geelhoed E, Jenkins SC. Reduction in hospitalisation 


\section{Artigo de revisão}

following pulmonary rehabilitation in patients with COPD. Australian health review : a publication of the Australian Hospital Association. 2008;32(3):415-422.

22. Trevisan ME, Porto AS, Pinheiro TM. Influência do treinamento da musculatura respiratória e de membros inferiores no desempenho funcional de indivíduos com DPOC. Fisioterapia e Pesquisa. 2010;17:209-213.

23. Ribeiro KTA, Costa D, Pêgas J. et al. Efeitos de um programa de reabilitação pulmonar em pacientes com doença pulmonar obstrutiva crônica (DPOC). Rev biociên. 2005;11(1-2):63-68.

24. Ike D, Jamami M, Marino DM, et al. Efeitos do exercício resistido de membros superiores na força muscular periférica e na capacidade funcional do paciente com DPOC. Fisioterapia em Movimento. 2010;23:429-437.

25. Dourado VZ, Antunes LC, Tanni SE, et al. Factors associated with the minimal clinically important difference for health-related quality of life after physical conditioning in patients with COPD. J Bras Pneumol. 2009;35(9):846-853.

26. Grosbois JM, Gicquello A, Langlois C, et al. Long-term evaluation of home-based pulmonary rehabilitation in patients with COPD. Int J Chron Obstruct Pulmon Dis. 2015;10:2037-2044.

27. Zanchet RC, Viegas CAA, Lima T. A eficácia da reabilitação pulmonar na capacidade de exercício, força da musculatura inspiratória e qualidade de vida de portadores de doença pulmonar obstrutiva crônica. Jornal Brasileiro de Pneumologia. 2005;31:118-124.

28. Costa CCLBS, Canterle DB, Souza RM, et al. Analysis of strength, quality of life, and tolerance to exercise in chronic pulmonary disease. R Bras Ci e Mov. 2014;22(2):27-35.

29. Sousa JBFR, G. Volpe, M. S. Effects of a standard pulmonary rehabilitation program after a minimal period of treatment. $R$ Bras Ci e Mov. 2014;22(3):126-132.
30. Zanini A, Aiello M, Cherubino F, et al. The one repetition maximum test and the sit-to-stand test in the assessment of a specific pulmonary rehabilitation program on peripheral muscle strength in COPD patients. Int J Chron Obstruct Pulmon Dis. 2015; 10:2423-2430.

31. Benton MJ, Wagner CL. Effect of single-set resistance training on quality of life in COPD patients enrolled in pulmonary rehabilitation. Respir Care. 2013;58(3):487-493.

32. Pothirat C, Chaiwong W, Phetsuk N. Efficacy of a simple and inexpensive exercise training program for advanced chronic obstructive pulmonary disease patients in community hospitals. J Thorac Dis. 2015:7(4):637-643.

33. Landal AC, Monteiro F, Hevely BCS, et al. Fatores associados à melhora da composição corporal em indivíduos com DPOC após treinamento físico. Fisioterapia em Movimento. 2014;27:633-641.

34. Araujo CLP, Karloh, M, Santos K, et al. Pulmonary rehabilitation in Chronic Obstructive Pulmonary Disease. ABCS Health Sci. 2014;30(1):56-60.

35. Ramos EM, de Toledo-Arruda AC, Fosco LC, et al.The effects of elastic tubing-based resistance training compared with conventional resistance training in patients with moderate chronic obstructive pulmonary disease: a randomized clinical trial. Clin Rehabil. 2014;28(11):1096-1106.

36. Calik-Kutukcu E, Arikan H, Saglam M, et al. Arm strength training improves activities of daily living and occupational performance in patients with COPD. Clin Respir J. 2015 Dec 1 [Epub ahead of print].

37. Menon MK, Houchen L, Harrison S, et al. Ultrasound assessment of lower limb muscle mass in response to resistance training in COPD. Respir Res. 2012;13:119 